\title{
Early-Onset Graft Pyelonephritis Is Predictive of Long-Term Outcome of Renal Allografts
}

\author{
Dong Ho Shin, ${ }^{1}$ Eun Jung Kim, ${ }^{1}$ Samuel Lee, ${ }^{2}$ Soo Jin Kim ${ }^{1}$ and Jieun $\mathrm{Oh}^{1,3}$ \\ ${ }^{1}$ Department of Internal Medicine, Kangdong Sacred Heart Hospital, Hallym University, Seoul, Korea \\ ${ }^{2}$ Department of Surgery, Kangdong Sacred Heart Hospital, Hallym University, Seoul, Korea \\ ${ }^{3}$ Department of Internal Medicine, Kangdong Sacred Heart Hospital, Hallym Kidney Research Institute, Hallym \\ University, Seoul, Korea
}

\begin{abstract}
Urinary tract infection (UTI) is the most common bacterial infection encountered in kidney transplant recipients. Graft pyelonephritis (GPN) is associated with acute kidney injury and renal allograft scarring. However, the influence of GPN on renal allograft outcome in kidney transplant recipients remains controversial. Two hundred sixty-five kidney transplant recipients were evaluated for the impact of earlyonset GPN on renal allograft functions between January 2001 and December 2011. Early-onset GPN was defined as the first GPN episode occurring within 6 months after kidney transplantation. Thirty recipients $(11.3 \%)$ were diagnosed with early-onset GPN. During the mean follow-up period of $69.1 \pm 28.9$ months, $56(21.1 \%)$ recipients showed renal allograft outcomes of a $>30 \%$ reduction in the estimated glomerular filtration rate (eGFR) over 2 years. The poor outcome was significantly more frequent in the early-onset GPN group (13 patients; 43.3\%) than in those without early-onset GPN (43 patients; $18.3 \%)(P=0.002)$. Moreover, the linear mixed model revealed a significant difference in the eGFR decline rate over time between the two groups $(P<0.001)$. Kaplan-Meier analysis showed that renal allograft event-free survival was significantly lower in the early-onset GPN group $(P=0.006)$. Multivariate Cox regression analyses revealed that early-onset GPN was independently predictive of poor renal allograft outcomes (hazard ratio, 1.96; $95 \%$ confidence interval, 1.02-3.77; $P=0.04$ ). In conclusion, early-onset GPN is independently associated with impaired renal functions in kidney transplant recipients. Thus, early-onset GPN could be a predictor for long-term outcome of renal allografts.
\end{abstract}

Keywords: allograft; glomerular filtration rate; kidney transplantation; outcome; pyelonephritis

Tohoku J. Exp. Med., 2015 July, 236 (3), 175-183. C 2015 Tohoku University Medical Press

\section{Introduction}

Urinary tract infection (UTI) in kidney transplant recipients is directly attributable to pathogen exposure during the early postoperative period and to immunosuppressive therapy (Rubin and Tolkoff-Rubin 1991; Goya et al. 1997; Schmaldienst and Horl 1998). Although improved surgical procedures, rapid urethral catheter removal, and antibiotic prophylaxis have reduced the incidence of UTI during the immediate postoperative period (Sagalowsky et al. 1983; Rabkin et al. 1998), the use of more potent immunosuppressive drugs to reduce the incidence of rejection predisposes kidney transplant recipients to increased risks of UTI (de Souza and Olsburgh 2008).

UTI is the most common infectious complication affecting kidney transplant recipients, and its incidence is much higher among kidney transplant recipients than in the general population (Abbott et al. 2004; Chuang et al. 2005). While these infections are considered relatively benign and are easily managed in outpatient clinics (Brown 2002), the finding from one study suggested that late UTI is not benign and is associated with increased risks of death and renal allograft loss (Abbott et al. 2004). However, their study did not establish whether the UTI was the direct cause of death or whether UTI was simply a marker for serious underlying disease. Additionally, most studies have not distinguished between simple UTI and graft pyelonephritis (GPN) (Massy et al. 1996; Giral et al. 2002).

GPN is associated with frequent hospitalizations and acute kidney injury. The findings from some studies have shown that GPN is associated with interstitial scarring in renal allografts (Dupont et al. 2007) and that it can activate an alloimmune response to the donor organ and subsequently contribute to acute or chronic rejection (Audard et al. 2005; Locke et al. 2009). In a previous cohort study, the occurrence of early-onset GPN following kidney transplantation was significantly associated with increased rates of renal allograft loss (Giral et al. 2002). Conversely, Abbott

Received March 20, 2015; revised and accepted May 25, 2015. Published online June 16, 2015; doi: 10.1620/tjem.236.175.

Correspondence: Jieun Oh, M.D., Ph.D., Department of Internal Medicine, Kangdong Sacred Heart Hospital, Hallym Kidney Research Institute, Hallym University, 150 Seongan-ro, Gangdong-gu, Seoul 134-701, Korea.

e-mail: jieunmd@gmail.com 
et al. (2004) demonstrated the association between lateonset GPN and subsequent renal allograft loss. However, Kamath et al. (2006) suggested that GPN did not contribute independently to poor renal allograft outcomes. In other words, recipients with GPN were more prone to the development of bacteremia, acute rejection, and cytomegalovirus (CMV) disease, which could lead to poor renal allograft outcomes (Kamath et al. 2006). Hence, the impact of GPN on long-term renal allograft outcomes remains still controversial. Therefore, we undertook a retrospective study to determine the risk factors for early-onset GPN following kidney transplantation and to explore the effect of earlyonset GPN on glomerular filtration rate (GFR) changes in kidney transplant recipients.

\section{Methods}

\section{Patients}

We conducted a retrospective cohort study at Kangdong Sacred Heart Hospital, which is a 600-bed teaching hospital where 462 kidney transplants have been performed in the last 30 years. Kidney transplantations were performed on 308 patients between January 2001 and December 2011. Of these patients, 43 were excluded, because they underwent simultaneous kidney-pancreas transplant ( $\mathrm{n}=$ $11)$, they had positive crossmatches $(n=7)$, they were dying or undergoing renal allograft losses within the first 6 months after kidney transplantation $(n=5)$, they were accompanied by the rapid deterioration of the renal allografts, caused by cardiovascular events during the first 6 months after kidney transplantation $(n=4)$, they had estimated GFRs (eGFR) of $<10 \mathrm{ml} / \mathrm{min}$ per $1.73 \mathrm{~m}^{2}$ during the first 2 years after kidney transplantation $(n=5)$, and they had follow-up duration of $<36$ months $(\mathrm{n}=11)$. The remaining 265 recipients were included in this study.

\section{Ethics statement}

This study was carried out in accordance with the Declaration of Helsinki and approved by the Institutional Review Board (IRB) of Kangdong Sacred Heart Hospital (Approval number: 14-2-46). None of the transplant donors were from vulnerable populations or were subject to coercion. All of the patients who participated in this study were aware of this investigation; however, given that this was a retrospective medical records-based study and the subjects were anonymized, the IRB waived the need for written consent from the patients.

\section{Definitions}

GPN was defined as the simultaneous presence of fever and a urine culture showing significant bacterial growth of $>10^{5}$ colonyforming units $/ \mathrm{ml}$ and/or bacteremia accompanied by one or more of the following: graft pain, chills, and/or cystitis (Rubin 1994). Earlyonset GPN was defined as the first GPN episode that occurred within 6 months after kidney transplantation. Acute rejection was suspected in recipients with established graft renal function and who experienced within 1-2 days a rapid increase in their plasma creatinine concentration of $10-25 \%$ over baseline with or without decreased urine output, graft tenderness, or fever in the absence of other obvious causes of acute renal allograft dysfunction (European Expert Group on Renal Transplantation et al. 2000). Acute rejection was diagnosed on the basis of histological examinations of the graft renal biopsy samples, if possible. Delayed graft function (DGF) was defined as the necessity for dialysis during the first week after transplantation (Sagedal et al. 2002). CMV disease was defined as the presence of fever with one or more of the following: leukopenia, gastrointestinal disease, pancreatitis, hepatitis, pneumonitis, or nephritis as well as virological proof obtained using the quantitative polymerase chain reaction or histological evidence of the endothelial cell inclusion of viral particles (Ljungman et al. 2002).

\section{Data collection}

Data were collected regarding the dialysis modality and duration before kidney transplantation, recipients' initial renal disease, recipients' age and gender, use of cadaveric or living-related donor, cold ischemic time, and the serum creatinine. Additionally, post-graft data including the occurrence of CMV disease and acute rejection were assessed. The eGFRs $\left(\mathrm{ml} / \mathrm{min} / 1.73 \mathrm{~m}^{2}\right)$ were calculated using the Chronic Kidney Disease Epidemiology Collaboration (CKD-EPI) equation (Levey et al. 2009). Recipients were seen at our institution every 2 weeks during the first 3 months after transplantation, monthly up to the first year after transplantation, and then every 2 months after the first year following transplantation. At each visit, blood samples were obtained for serum creatinine and immunosuppressive drug monitoring. Furthermore, all recipients were asked about the presence of UTI symptoms, and urine cultures, microscopic urinalysis, and leukocyte esterase stick tests were performed regardless of symptoms for the first 6 months after transplantation. Then, only microscopic urinalysis and leukocyte esterase stick tests were conducted at each visit. Additional urine cultures were performed if the kidney transplant recipients developed UTI symptoms.

\section{Immunosuppressive regimens}

All of the recipients were initially maintained on a triple-drug immunosuppressive regimen that included cyclosporine $(10 \mathrm{mg} / \mathrm{kg} /$ day, adjusted to a target level of $100-300 \mathrm{ng} / \mathrm{ml})$ or tacrolimus $(0.1$ $\mathrm{mg} / \mathrm{kg} /$ day, adjusted to a target level of $10-15 \mathrm{ng} / \mathrm{ml}$ for the first month, then $5-10 \mathrm{ng} / \mathrm{ml}$ for maintenance), prednisone $(1 \mathrm{mg} / \mathrm{kg} / \mathrm{day}$, tapered to $5 \mathrm{mg}$ weekly), and azathioprine $(1.5 \mathrm{mg} / \mathrm{kg} /$ day $)$ or mycophenolate mofetil (MMF) (500 mg-2 g/day).

\section{Antibiotic prophylaxis}

All of the recipients were administered antibiotic prophylaxis consisting of $2 \mathrm{~g}$ intravenous cefazolin intraoperatively. The postoperative antibiotic prophylaxis consisted of trimethoprim-sulfamethoxazole (160 mg/800 mg daily) administered during the first 6 months to prevent bacterial infections and Pneumocystis jirovecii pneumonia. Recipients who were allergic to trimethoprim-sulfamethoxazole were treated with any of the oral quinolones such as ciprofloxacin $(500 \mathrm{mg}$ daily). All of the recipients also received oral fluconazole $(50 \mathrm{mg}$ daily) for 1 month. In the case of a CMV seropositive donor/CMV seronegative recipient, CMV prophylaxis was mostly performed using valganciclovir at a dose of $900 \mathrm{mg}$ daily for 3 months, which was adjusted according to renal allograft function.

\section{Surgical procedure}

A double-J ureteric stent was placed during surgery, when indicated, and was removed 2 weeks after the kidney transplantation. If the patient developed GPN with the stent in situ, the stent was removed immediately. The common indications for stent placement included thin bladder, anatomic outflow restrictions, and ureteric anastomoses into the intestinal segments. The indwelling bladder 
catheter was removed 5 days after kidney transplantation.

\section{Study endpoints}

The study's endpoints were renal allograft loss and a $>30 \%$ reduction in the eGFR compared with the baseline renal allograft function over 2 years. Renal allograft loss was defined as the initiation of renal replacement therapy that included permanent hemodialysis, peritoneal dialysis, or kidney re-transplantation.

\section{Statistical analyses}

All of the Statistical analyses were performed using SPSS software, version 17.0 (SPSS Inc., Chicago, Illinois, USA). The continuous variables were expressed as mean \pm standard deviation and the categorical variables were express as numbers (percentages). To compare the differences between the groups, Student's $t$ test, the $\chi^{2}$ test, or Fisher's exact test were used. The Kolmogorov-Smirnov test was used to analyze the normality of the distributions of the parameters. Nonparametric variables were expressed as medians and interquartile range [IQR] and they were compared using the MannWhitney test. Multivariate logistic regression, which included all of the covariates with $P$ values $<0.1$ in the univariate analysis, was performed to identify the potential independent risk factors associated with early-onset GPN. The slope of the decline in renal allograft function over time was calculated from the linear regression analysis of serial eGFRs for each patient, and the slope was expressed as the regression coefficient $\left(\mathrm{ml} / \mathrm{min} / \mathrm{year} / 1.73 \mathrm{~m}^{2}\right)$. The changes in the eGFRs over time were compared between patients with and without early-onset GPN using a linear mixed model. Cumulative survival curves were generated using the Kaplan-Meier method to determine the effect of early-onset GPN on the renal allograft outcomes, and the between-group renal allograft event-free survival was compared using a log-rank test. The independent prognostic value of early-onset GPN on the renal allograft outcome was determined using multivariate Cox proportional hazards regression analysis, which included all of the covariates with $P$ values $<0.05$ in the univariate analysis.

\section{Results}

\section{Recipients' baseline characteristics}

The baseline demographic, clinical and biochemical data of the kidney transplant recipients are presented in Table 1. Of the 265 kidney transplant recipients, 30 recipients $(11.3 \%)$ had early-onset GPN. The mean age of the recipients was 49.5 years, and 134 (50.6\%) patients were women. Compared to recipients without early-onset GPN, those with early-onset GPN had more proportions of women $(73.3 \%$ vs. $47.4 \%$; $P=0.01)$, more use of MMFbased regimens $(96.7 \%$ vs. $65.5 \% ; P=0.01)$, and more diabetes mellitus (DM) $(46.7 \%$ vs. $21.3 \% ; P=0.02)$ or glomerulonephritis $(33.3 \%$ vs. $14.5 \% ; P=0.01)$ as the initial end-stage renal disease. Additionally, CMV disease (30.0\% vs. $6.4 \% ; P<0.001)$ and the occurrence of bacteremia $(10.0 \%$ vs. $1.7 \% ; P=0.03)$ were more prevalent in recipients with early-onset GPN when compared to those without early-onset GPN. In recipients with early-onset GPN, CMV disease manifested after early-onset GPN episodes in six recipients, while it preceded early-onset GPN in two recipients, and it occurred at the same time in one recipient. Of note, in recipients with early-onset GPN, all bacteremia was induced by GPN.

However, there were no differences between recipients with early-onset GPN and those without early-onset GPN with respect to age, the eGFR following kidney transplantation, the dialysis duration and modality before kidney transplantation, the type of kidney transplant, the proportion of subjects with vesicoureteral reflux, DGF, and acute rejection following kidney transplantation.

\section{GPN episodes}

Among the 265 kidney transplant recipients, 36 (13.2\%) recipients presented with 42 episodes of GPN during the study period as follows: one episode in 31 recipients; two episodes in four recipients; and three episodes in one recipient, resulting in an incidence of 2.8 episodes per 100 patient-years. The median time interval between kidney transplantation and the first GPN episode was 19 days (IQR: 1-117 days). Specifically, 30 (11.3\%) recipients experienced their first GPN episode within the first 6 months of kidney transplantation. Among these, 27 recipients developed GPN once only, and three recipients experienced recurrent episodes during the study period as follows: two episodes in two recipients and three episodes in one recipient. Among the recurrent episodes, five occurred within the first 6 months of kidney transplantation. Therefore, 32 out of 42 GPN episodes (76.2\%) occurred within the first 6 months of kidney transplantation.

\section{Risk factors for early-onset GPN}

Risk factors for the development of early-onset GPN after kidney transplantation are analyzed in Table 2. The variables that were independently related to the development of early-onset GPN in the final multivariate analysis were female sex (odds ratio [OR], 2.94; 95\% confidence interval [CI], 1.11-7.78; $P=0.03$ ), DM (OR, 3.76; 95\% CI, 1.05-13.43; $P=0.04$ ) or glomerulonephritis (OR, 5.34; $95 \% \mathrm{CI}, 1.42-20.07 ; P=0.01)$ as the initial end-stage renal disease, use of MMF-based regimens (OR, 9.72; 95\% CI, 1.24-76.31; $P=0.03$ ), and CMV disease following kidney transplantation (OR, 5.30; 95\% CI, 1.77-15.87; $P=0.003$ ).

Comparison of renal allograft function over time in recipients with and without early-onset $G P N$

As shown in Fig. 1 and Table 3, recipients with earlyonset GPN had similar baseline eGFRs compared with recipients without early-onset GPN. At 4 years, the eGFRs became significantly lower in recipients who experienced early-onset GPN $(P<0.01)$. Additionally, the overall rate of the decline in the eGFRs was significantly greater in recipients with early-onset GPN compared with recipients without early-onset GPN $\left(-4.8 \pm 6.5 \mathrm{ml} / \mathrm{min} /\right.$ year $/ 1.73 \mathrm{~m}^{2}$ vs. $-2.1 \pm 6.8 \mathrm{ml} / \mathrm{min} /$ year $\left./ 1.73 \mathrm{~m}^{2} ; P=0.04\right)$. A linear mix model revealed a significant difference between recipients with and those without early-onset GPN with respect to in the rate of the eGFR decline over time $(P<0.001)$. 
Table 1. Demographic and clinical characteristics of the 265 kidney transplant recipients according to early-onset graft pyelonephritis.

\begin{tabular}{|c|c|c|c|c|}
\hline Variable & $\begin{array}{c}\text { Total } \\
(\mathrm{n}=265)\end{array}$ & $\begin{array}{l}\text { With early-onset GPN }{ }^{a} \\
\qquad(\mathrm{n}=30)\end{array}$ & $\begin{array}{l}\text { Without early-onset GPN } \\
\qquad(\mathrm{n}=235)\end{array}$ & $P$ value \\
\hline Age (years) & $49.5 \pm 9.1$ & $49.6 \pm 8.9$ & $49.5 \pm 9.1$ & 0.97 \\
\hline Female, n $(\%)$ & $134(50.6)$ & $22(73.3)$ & $112(47.4)$ & 0.01 \\
\hline Creatinine (mg/dL) & $1.2 \pm 0.6$ & $1.2 \pm 0.5$ & $1.2 \pm 0.6$ & 0.73 \\
\hline $\mathrm{eGFR}\left(\mathrm{ml} / \mathrm{min} / 1.73 \mathrm{~m}^{2}\right)$ & $73.5 \pm 25.2$ & $73.3 \pm 35.2$ & $73.5 \pm 23.7$ & 0.97 \\
\hline \multicolumn{5}{|l|}{ Initial end-stage renal disease } \\
\hline Hypertension, $\mathrm{n}(\%)$ & $60(22.6)$ & $3(10.0)$ & $57(24.3)$ & 0.08 \\
\hline Diabetes, n (\%) & $64(24.2)$ & $14(46.7)$ & $50(21.3)$ & 0.002 \\
\hline Glomerulonephritis, n (\%) & $44(16.6)$ & $10(33.3)$ & $34(14.5)$ & 0.02 \\
\hline CIN, n (\%) & $55(20.8)$ & $2(6.7)$ & $53(22.6)$ & 0.04 \\
\hline Polycystic kidney, n (\%) & $20(7.5)$ & $1(3.3)$ & $19(8.1)$ & 0.71 \\
\hline Unknown, n (\%) & $22(8.3)$ & $0(0.0)$ & $22(9.4)$ & 0.15 \\
\hline Dialysis duration before KT (years) & $5.1 \pm 3.6$ & $5.2 \pm 3.2$ & $5.1 \pm 3.6$ & 0.87 \\
\hline Dialysis modality before KT & & & & 0.54 \\
\hline Hemodialysis, n (\%) & $182(68.7)$ & $21(70.0)$ & $161(68.5)$ & \\
\hline Peritoneal dialysis, $\mathrm{n}(\%)$ & $68(25.7)$ & $9(30.0)$ & $59(25.1)$ & \\
\hline Combine, $\mathrm{n}(\%)$ & $10(3.8)$ & $0(0.0)$ & $10(4.3)$ & \\
\hline Transplantation type & & & & 0.54 \\
\hline Living, n (\%) & $59(22.3)$ & $8(26.7)$ & $51(21.7)$ & \\
\hline Deceased, n (\%) & $206(77.7)$ & $22(73.3)$ & $90(78.3)$ & \\
\hline Vesicoureteral reflux, n (\%) & $86(32.5)$ & $12(40.0)$ & $74(31.5)$ & 0.35 \\
\hline \multicolumn{5}{|l|}{ Immunosuppressive regimen } \\
\hline Tacrolimus, n (\%) & $180(67.9)$ & $24(80.0)$ & $156(66.4)$ & 0.13 \\
\hline Cyclosmoprine, n (\%) & $83(31.3)$ & $6(20.0)$ & $77(32.8)$ & 0.16 \\
\hline Mycophenolate mofetil, n (\%) & $183(69.1)$ & $29(96.7)$ & $154(65.5)$ & 0.001 \\
\hline Azathioprine, n (\%) & $80(30.2)$ & $1(3.3)$ & $79(33.6)$ & 0.001 \\
\hline Number of AGPN episode & & & & 0.17 \\
\hline One, n (\%) & $31(11.6)$ & $27(90.0)$ & $4(1.7)^{b}$ & \\
\hline Two, n (\%) & $4(1.5)$ & $2(6.7)$ & $2(0.8)^{b}$ & \\
\hline Three, n (\%) & $1(0.4)$ & $1(3.3)$ & $0(0.0)$ & \\
\hline DGF, n (\%) & $54(20.4)$ & $5(16.7 \%)$ & $49(20.9)$ & 0.59 \\
\hline Acute rejection ( $\geq 1$ episode) & $44(16.6)$ & $4(13.3)$ & $40(17.0)$ & 0.80 \\
\hline CMV disease & $24(9.1)$ & $9(30.0)$ & $15(6.4)$ & $<0.001$ \\
\hline Bacteremia & $7(2.6)$ & $3(10.0)$ & $4(1.7)$ & 0.03 \\
\hline
\end{tabular}

The values are express as the means \pm standard deviations, or number (percentage).

CIN, chronic interstitial nephropathy; CMV, cytomegalovirus; DGF, delayed graft function; eGFR, estimated glomerular filtration rate; GPN, graft pyelonephritis; KT, kidney transplantation.

aThe first graft pyelonephritis episode occurring within 6 months after kidney transplantation.

${ }^{\mathrm{b}}$ The first graft pyelonephritis episode occurring after 6 months after kidney transplantation.

Renal allograft outcomes in recipients with and without early-onset GPN

None of the recipients progressed to renal allograft loss before $30 \%$ reduction in eGFR had occurred during the mean follow-up duration of $69.1 \pm 28.9$ months. A $>30 \%$ reduction in the eGFR over 2 years occurred more often in recipients with early-onset GPN (13 patients out of 30 patients; 43.3\%) compared with recipients without earlyonset GPN (43 patients out of 235 patients; 18.3\%), resulting in rates of 8.60 and 3.56 per 100 patient-years, respectively $(P=0.002)$ (Table 4$)$. The renal allograft loss incidence was also significantly higher in recipients with early-onset GPN relative to recipients without early-onset GPN (1.99 vs. 0.41 per 100 patients-years; $P=0.05$ ). The relative risks for a $>30 \%$ reduction in the eGFR and renal allograft loss in recipients with early-onset GPN were 3.42 (95\% CI, 1.54-7.56; $P=0.002)$ and 5.11 (95\% CI, 1.1622.59; $P=0.05$ ), respectively (Table 4). The Kaplan-Meier estimate also indicated that renal allograft event-free survival was significantly lower in recipients with early-onset GPN (Fig. 2). 
Table 2. Multivariate analysis for risk factors associated with early-onset graft pyelonephritis.

\begin{tabular}{llc}
\hline \multicolumn{1}{c}{ Variables } & \multicolumn{1}{c}{ OR $(95 \% \mathrm{CI})$} & $P$ value \\
\hline Age & $1.00(0.96-1.05)$ & 0.86 \\
Female & $2.94(1.11-7.78)$ & 0.03 \\
Initial end-stage renal disease & & \\
$\quad$ Diabetes & $3.76(1.05-13.43)$ & 0.04 \\
Hypertension & $0.85(0.18-4.08)$ & 0.86 \\
$\quad$ Glomerulnonephritis & $5.34(1.42-20.07)$ & 0.01 \\
MMF-based regimen & $9.72(1.24-76.31)$ & 0.03 \\
CMV disease & $5.30(1.77-15.87)$ & 0.003 \\
\hline
\end{tabular}

$\mathrm{OR}$, odds ratio; $\mathrm{CI}$, confidence interval; MMF, mycophenolate mofetil; CMV, cytomegalovirus.

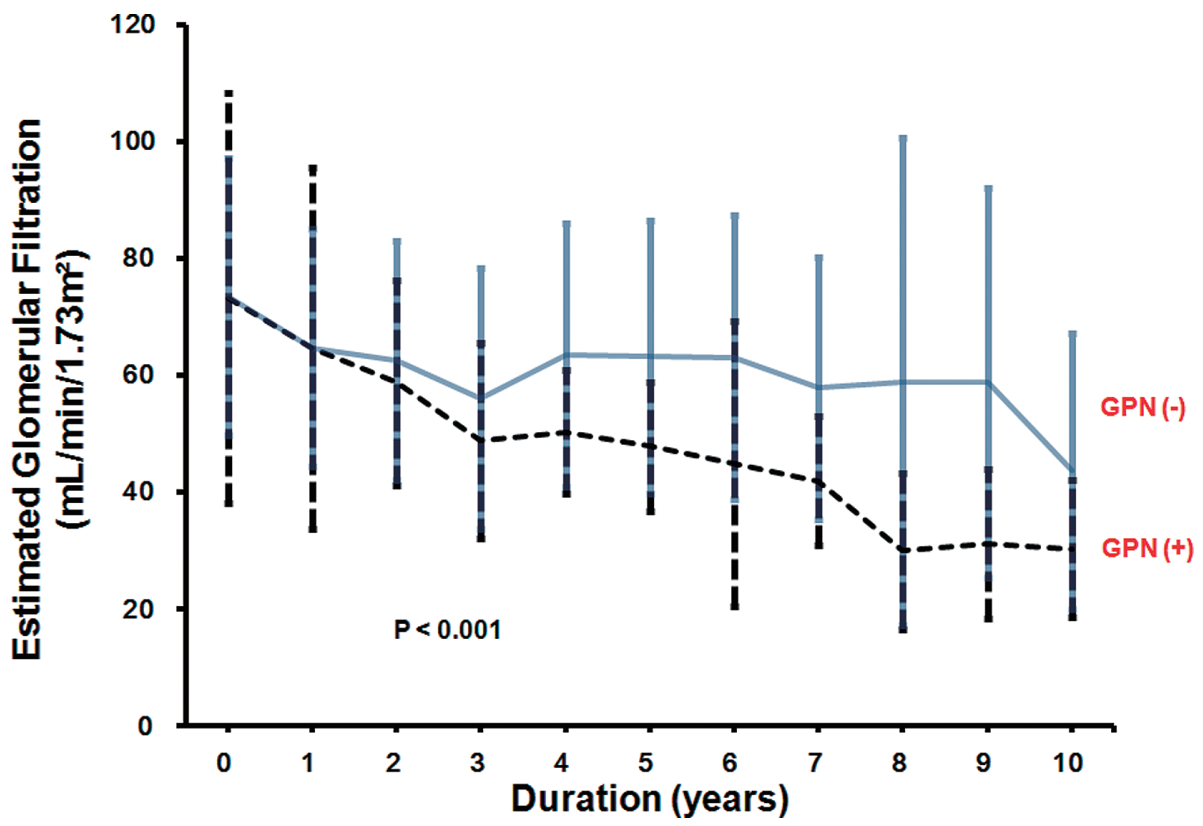

Fig. 1. Change in the estimated glomerular filtration rate over time in kidney transplant recipients.

The dotted line and the solid line depict kidney transplant recipients with early-onset graft pyelonephritis (GPN) $(\mathrm{n}=$ $30)$, shown as GPN $(+)$, and those without early-onset GPN $(\mathrm{n}=235)$, shown as GPN $(-)$, respectively. Data are presented as the means and standard deviations. A liner mixed model revealed a significant difference in the rate of the eGFR decline over time between the groups $(P<0.001)$.

Independent predictive value of the impact of early-onset GPN on renal allograft function

Risk factors for reaching a $>30 \%$ reduction in the eGFR and renal allograft loss are analyzed in Table 5. The variables that were related to a higher risk with renal allograft outcome in univariate Cox regression analysis were acute rejection (hazard ratio $[\mathrm{HR}], 3.14 ; 95 \% \mathrm{CI}$, 1.82-5.41; $P<0.001$ ), early-onset GPN (HR, 2.31; 95\% CI, $1.24-4.31 ; P=0.01$ ), DGF (HR, $1.80 ; 95 \%$ CI, 1.03-3.13; $P$ $=0.04)$, CMV disease (HR, 3.04; 95\% CI, 1.63-5.67; $P<$ 0.001 ), and bacteremia (HR, 5.15; 95\% CI, 2.33-11.41; $P<$ $0.001)$. The impact of early-onset GPN on renal allograft function remained significant even after adjusting for acute rejection, DGF, CMV disease, and bacteremia (HR, 1.96; 95\% CI, 1.02-3.77; $P=0.04$ ).

\section{Discussion}

Given previously reported conflicting results, the adverse effect of GPN on renal allograft function has not been established. Although findings from some studies have demonstrated that GPN exerts an adverse effect on renal allograft function (Giral et al. 2002; Pelle et al. 2007), whether GPN had a direct effect on renal allograft function or was simply a marker for serious underlying diseases such as bacteremia, CMV infection, and acute rejection has not been established. Our results suggest that early-onset GPN following kidney transplantation is associated with the deterioration of renal allografts that is independent of bacteremia, CMV infection, and acute rejection.

The prevalence of GPN found in this study was similar to that determined by others (13-16.5\%) (Giral et al. 2002; Kamath et al. 2006). Additionally, most GPN episodes in 
Table 3. Comparison of changes in the estimate glomerular filtration rates over time in kidney transplant recipients with and without early-onset graft pyelonephritis.

\begin{tabular}{lccc}
\hline \multicolumn{1}{c}{ Variables } & $\begin{array}{c}\text { With early-onset } \\
\mathrm{GPN}^{\mathrm{a}} \\
(\mathrm{n}=30)\end{array}$ & $\begin{array}{c}\text { Without early-onset } \\
\text { GPN } \\
(\mathrm{n}=235)\end{array}$ & $P$ value \\
\hline eGFR $\left(\mathrm{ml} / \mathrm{min} / 1.73 \mathrm{~m}^{2}\right)$ & & & 0.97 \\
$\quad$ At baseline & $73.3 \pm 35.2$ & $73.5 \pm 23.7$ & 0.97 \\
1 year & $64.6 \pm 30.9$ & $64.8 \pm 20.4$ & 0.38 \\
2 years & $58.8 \pm 17.6$ & $62.6 \pm 20.5$ & 0.14 \\
3 years & $48.9 \pm 16.7$ & $56.2 \pm 22.3$ & $<0.001$ \\
4 years & $50.4 \pm 10.5$ & $63.5 \pm 22.6$ & 0.01 \\
5 years & $47.9 \pm 11.1$ & $63.2 \pm 23.3$ & 0.001 \\
6 years & $45.0 \pm 24.4$ & $63.1 \pm 24.3$ & 0.03 \\
7 years & $42.0 \pm 11.1$ & $57.9 \pm 22.4$ & 0.03 \\
8 years & $30.0 \pm 13.4$ & $59.0 \pm 41.7$ & 0.02 \\
9 years & $31.2 \pm 12.8$ & $58.8 \pm 33.4$ & 0.02 \\
10 years & $30.4 \pm 11.8$ & $43.7 \pm 23.6$ & 0.04 \\
The slope of decline & $-4.8 \pm 6.5$ & $-2.1 \pm 6.8$ & \\
in eGFR $\left(\mathrm{ml} / \mathrm{min} /\right.$ year $\left./ 1.73 \mathrm{~m}^{2}\right)$ & & & \\
\hline
\end{tabular}

eGFR, estimated glomerular filtrations rate; GPN, graft pyelonephritis.

Values are expressed as the means \pm standard deviations. The estimated glomerular filtration rate was calculated using the Chronic Kidney Disease Epidemiology Collaboration formula.

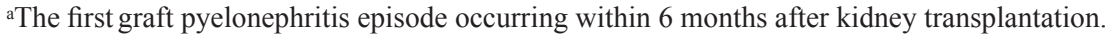

Table 4. Incidence of recipients with $30 \%$ reduction in the estimated glomerular filtration rate or renal allograft loss according to earlyonset graft pyelonephritis.

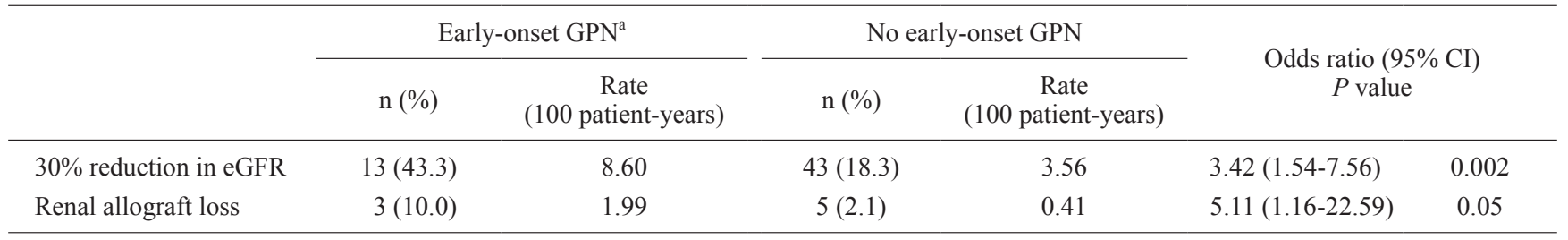

CI, confidence interval; eGFR, estimated glomerular filtration rate; GPN, graft pyelonephritis.

The estimated glomerular filtration rate was calculated using the Modification of Diet in Renal Disease Study Equation.

aThe first graft pyelonephritis episode occurring within 6 months after kidney transplantation.

these studies were diagnosed within the first 6 months after kidney transplantation. The higher rate of early-onset GPN among kidney transplant recipients is explained by the surgical and immunological trauma and the influence of early intensive immunosuppression.

The multivariate analysis enabled us to define a number of predictive variables for the development of earlyonset GPN. Importantly, glomerulonephritis was an independent predictive factor for early-onset GPN. Although the rationale for this previously undescribed association is far from clear, Fiorante et al. (2011) hypothesized that the presence of immune-compromising comorbidities in these patients, for example, systemic lupus erythematous or systemic vasculitis, or the amounts and duration of the pretransplant immunosuppressive regimens administered to transplant recipients might affect the incidence of earlyonset GPN after kidney transplantation. Additionally, being administered MMF-based immunosuppressive regimens was associated with a higher infection rate compared to other immunosuppressive regimen. MMF potently inhibits proliferation of human $\mathrm{T}$ - and B-lymphocytes and reduces recruitment of lymphocytes and monocytes to sites of inflammation, thus impairing both the cellular and humoral immunity directed towards infection (Allison et al. 1993). Furthermore, CMV infection was significantly associated with a higher risk of early-onset GPN in this study. In a majority (66.7\%), CMV disease followed an occurrence of early-onset GPN among recipients with early-onset GPN. Docke et al. (1994) suggested that the variety of cytokines released in response to the bacterial invasion of the urinary tract might trigger CMV replication by generating nuclear transcription factor kappa B. Therefore, our study supports the view that UTI reactivates CMV.

GPN after kidney transplantation may have important implications, for example, it may be associated with bacteremia and patients may require hospitalization. Although 


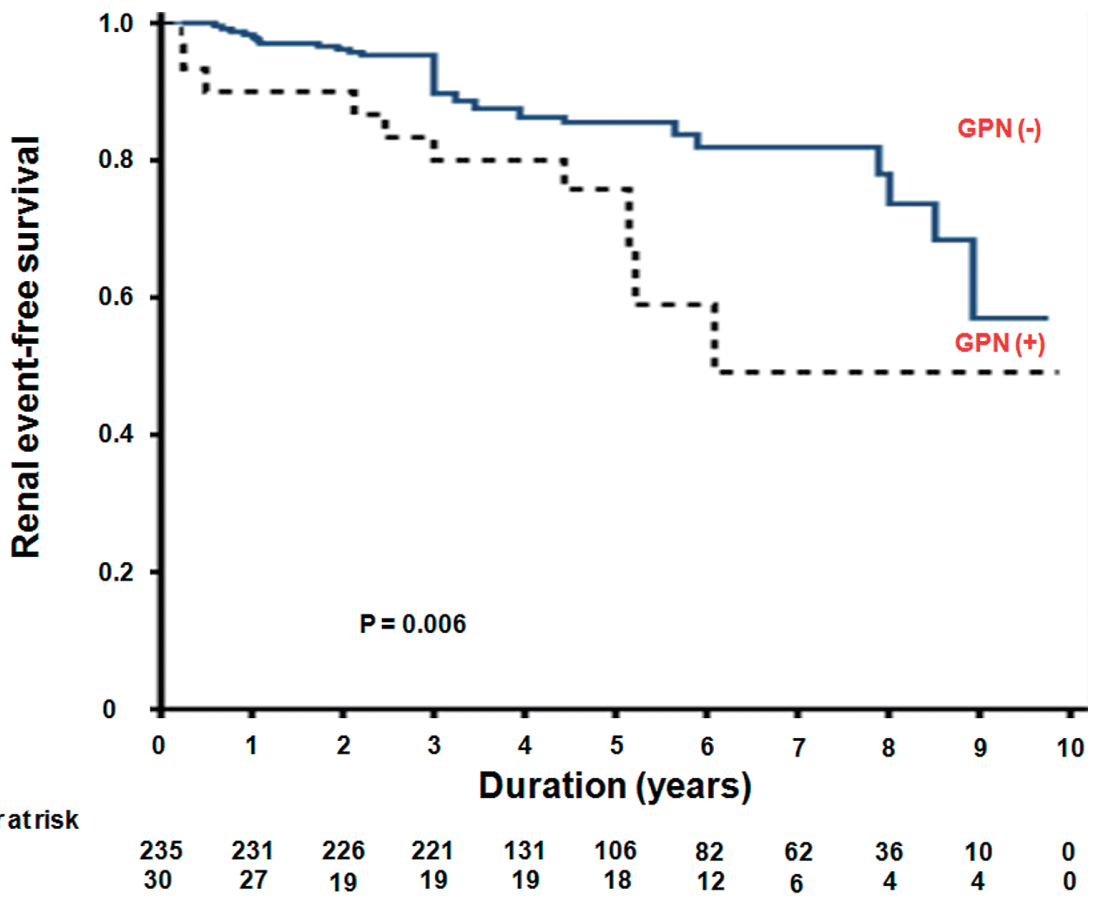

Fig. 2. Kaplan-Meier plot of renal allograft event-free survival in kidney transplantation.

The dotted line and the solid line depict kidney transplant recipients with early-onset graft pyelonephritis (GPN) $(\mathrm{n}=$ $30)$, shown as GPN $(+)$, and those without early-onset GPN ( $=235)$, shown as GPN $(-)$, respectively. Renal allograft events were defined as a greater than $30 \%$ reduction in the estimated glomerular filtration rate over 2 years and renal allograft loss. The cumulative renal allograft event-free survival was significantly higher in kidney transplant recipients without early-onset GPN $(P=0.006)$.

Table 5. Prediction of renal allograft outcomes using the Cox proportional hazards model.

\begin{tabular}{|c|c|c|c|c|}
\hline \multirow{2}{*}{ Variables } & \multicolumn{2}{|c|}{ Univariate analysis } & \multicolumn{2}{|c|}{ Multivariate analysis } \\
\hline & $\mathrm{HR}(95 \% \mathrm{CI})$ & $P$ value & $\mathrm{HR}(95 \% \mathrm{CI})$ & $P$ value \\
\hline Age (per 1 year) & $0.99(0.96-1.02)$ & 0.38 & - & - \\
\hline Female (vs. male) & $1.04(0.61-1.75)$ & 0.90 & - & - \\
\hline Creatinine (per $1 \mathrm{mg} / \mathrm{dL}$ ) & $0.80(0.45-1.42)$ & 0.45 & - & - \\
\hline \multicolumn{5}{|l|}{ Initial end-stage renal disease } \\
\hline Hypertension & $1.17(0.63-2.18)$ & 0.62 & - & - \\
\hline Diabetes & $1.29(0.72-2.31)$ & 0.39 & - & - \\
\hline Dialysis duration before KT (per 1 year) & $0.97(0.90-1.05)$ & 0.43 & - & - \\
\hline \multicolumn{5}{|l|}{ Transplantation type } \\
\hline Deceased (vs. living) & $1.08(0.57-2.05)$ & 0.81 & - & - \\
\hline Vesicoureteral reflux & $1.00(0.57-1.76)$ & 0.99 & - & - \\
\hline \multicolumn{5}{|l|}{ Immunosuppressive regimen } \\
\hline Tacrolimus & $1.02(0.59-1.78)$ & 0.93 & - & - \\
\hline Cyclosporine & $0.88(0.50-1.54)$ & 0.65 & - & - \\
\hline Early-onset GPN (vs. no early-onset GPN) & $2.31(1.23-4.31)$ & 0.01 & $1.96(1.02-3.77)$ & 0.04 \\
\hline DGF & $1.80(1.03-3.13)$ & 0.04 & $2.10(1.19-3.70)$ & 0.01 \\
\hline Acute rejection ( $\geq 1$ episode) & $3.14(1.82-5.41)$ & $<0.001$ & $2.57(1.44-4.58)$ & 0.001 \\
\hline CMV disease & $3.04(1.63-5.67)$ & $<0.001$ & $2.16(1.12-4.15)$ & 0.02 \\
\hline Bacteremia & $5.15(2.33-11.41)$ & $<0.001$ & $2.56(1.12-5.88)$ & 0.03 \\
\hline
\end{tabular}

CI, confidence interval; CMV, cytomegalovirus; DGF, delayed graft function; GPN, graft pyelonephritis; HR, hazard ratio; KT, kidney transplantation.

${ }^{a}$ The first graft pyelonephritis episode occurring within 6 months after renal transplantation. 
the findings from some studies have shown that GPN induces graft dysfunction (Giral et al. 2002; Pelle et al. 2007), the mechanism of graft dysfunction following GPN has not been clarified. The finding from one study suggested GPN could cause interstitial scars in renal allografts and a subsequent reduction in the functional nephron mass (Dupont et al. 2007). On the other hand, bacterial infection is also likely to induce the activation of the immune system, leading to acute or chronic rejection. Preliminary data have shown that proinflammatory events such as infections evoke a significant human leukocyte antigen specific antigen (HSA) increase (Locke et al. 2009). Eventually, increases in HSA escalate the risk of acute rejection (Locke et al. 2009). Additionally, Audard et al. (2005) reported two documented cases of acute rejection that occurred in the context of GPN, which strongly suggested that the immunological reaction was initiated by the infectious process. They suggested that bacterial products located within the graft regulate toll-like receptors, which (re)activate the alloreactive T-cells (Goldstein et al. 2003). Furthermore, high concentrations of cytokines, including tumor necrosis factor alpha, interleukin (IL)-1, IL-6, and IL-8 following GPN might strengthen the alloimmune response (Inston and Cockwell 2002). However, whether GPN triggers the activation of the immune system, which could lead to acute or chronic rejection, is uncertain. Giral et al. (2002) demonstrated that early-onset GPN episodes were significant determinants of renal allograft outcomes that were apparently independent of acute rejection episodes. These findings suggest that a previously described potential "danger signal," which claims that self constituents can trigger an immune response, could be insufficient, and that some regulatory mechanisms that occur following transplantation could be efficient (VanBuskirk et al. 2000). In line with their finding, the current study's findings showed that earlyonset GPN causes the deterioration of renal allograft function that is independent of acute rejection.

As the new immunosuppressive drugs have reduced the incidence of rejection and improved short-term graft survival, most kidney transplant recipients experience a chronic kidney disease (CKD) status (Meier-Kriesche et al. 2004). Most CKD clinical trials require long follow-up periods and large sample sizes, because the established renal endpoints, a doubling of the serum creatinine concentration from baseline or renal replacement therapy, used to document CKD progression are late events (Palmer et al. 2011). Thus, the same problems that occurred in CKD clinical trials have happened in kidney transplantation clinical trials. To overcome this limitation, Coresh et al. (2014) recently reported that lesser declines in the eGFR calculated using CKD-EPI equation, for example, a 30\% reduction over 2 years, could be considered an alternative endpoint for CKD progression. They suggested that declines in the eGFR that were smaller than a doubling of the serum creatinine concentrations occurred more commonly and were strongly and consistently associated with the risk of end- stage renal disease and mortality (Coresh et al. 2014). Although some studies have defined the renal outcome as an increase in the serum creatinine levels of $>0.33 \mathrm{mg} / \mathrm{dl}$ between 3 months and 1 year after kidney transplantation (Pelle et al. 2007; Fiorante et al. 2011), the representation of renal allograft loss using this renal outcome is difficult to represent to renal allograft loss because less deterioration in renal allograft function occurs during short time periods. However, in this study, the renal allograft outcome was defined as a $>30 \%$ reduction in the eGFR compared with the baseline renal allograft function over 2 years. Although eGFR formulas have been tested in kidney transplant recipients, no formula has been consistently shown to be superior to any other formula (Kidney Disease: Improving Global Outcomes (KDIGO) Transplant Work Group 2009). Therefore, the eGFR calculated using the CKD-EPI equation in this study, which was in contrast to other studies.

This study has some limitations. First, it was an uncontrolled retrospective study based on a small number of patients who underwent kidney transplantations at a single center. Thus, this study was limited in its assessments of some of the variables, which may have influenced the risk of GPN as well as the impact of GPN on renal allograft function. Second, it is difficult to assess the incidence of GPN after kidney transplantation, because these infections may either be asymptomatic or have atypical clinical presentations. Thus, GPN may be more common than we suspect clinically. Therefore, the impact of allograft infection on graft function may be underestimated. Third, in this cohort study, protocol renal allograft biopsies were not performed. Often, GPN induces subclinical allograft rejection, which has been reported to occur in about $30 \%$ of stable renal transplant patients, thereby contributing to chronic allograft nephropathy (Veronese et al. 2004). Therefore, the real incidence of allograft rejection following GPN might be underestimated.

In conclusion, we have shown that early-onset GPN is independently associated with poor renal function in kidney transplant recipients, suggesting that early-onset GPN could be a predictor for long-term renal allograft outcomes.

\section{Acknowledgments}

We thank the kidney transplant coordinators for their dedication to the care of the transplant recipients and for their help in the collection of data from these patients.

\section{Conflict of Interest}

The authors declare no conflict of interest.

\section{References}

Abbott, K.C., Swanson, S.J., Richter, E.R., Bohen, E.M., Agodoa, L.Y., Peters, T.G., Barbour, G., Lipnick, R. \& Cruess, D.F. (2004) Late urinary tract infection after renal transplantation in the United States. Am. J. Kidney Dis., 44, 353-362.

Allison, A.C., Kowalski, W.J., Muller, C.J., Waters, R.V. \& Eugui, E.M. (1993) Mycophenolic acid and brequinar, inhibitors of purine and pyrimidine synthesis, block the glycosylation of 
adhesion molecules. Transplant. Proc., 25, 67-70.

Audard, V., Amor, M., Desvaux, D., Pastural, M., Baron, C., Philippe, R., Pardon, A., Dahmane, D., Lang, P. \& Grimbert, P. (2005) Acute graft pyelonephritis: a potential cause of acute rejection in renal transplant. Transplantation, 80, 1128-1130.

Brown, P.D. (2002) Urinary tract infections in renal transplant recipients. Curr. Infect. Dis. Rep., 4, 525-528.

Chuang, P., Parikh, C.R. \& Langone, A. (2005) Urinary tract infections after renal transplantation: a retrospective review at two US transplant centers. Clin. Transplant., 19, 230-235.

Coresh, J., Turin, T.C., Matsushita, K., Sang, Y., Ballew, S.H., Appel, L.J., Arima, H., Chadban, S.J., Cirillo, M., Djurdjev, O., Green, J.A., Heine, G.H., Inker, L.A., Irie, F., Ishani, A., et al. (2014) Decline in estimated glomerular filtration rate and subsequent risk of end-stage renal disease and mortality. JAMA, 311, 2518-2531.

de Souza, R.M. \& Olsburgh, J. (2008) Urinary tract infection in the renal transplant patient. Nat. Clin. Pract. Nephrol., 4, 252-264.

Docke, W.D., Prosch, S., Fietze, E., Kimel, V., Zuckermann, H., Klug, C., Syrbe, U., Kruger, D.H., von Baehr, R. \& Volk, H.D. (1994) Cytomegalovirus reactivation and tumour necrosis factor. Lancet, 343, 268-269.

Dupont, P.J., Psimenou, E., Lord, R., Buscombe, J.R., Hilson, A.J. \& Sweny, P. (2007) Late recurrent urinary tract infections may produce renal allograft scarring even in the absence of symptoms or vesicoureteric reflux. Transplantation, $\mathbf{8 4}$, 351-355.

European Expert Group on Renal Transplantation (EBPG); European Renal Association (ERA-EDTA); European Society for Organ Transplantation (ESOT) (2000) European best practice guidelines for renal transplantation (part 1). Nephrol. Dial. Transplant., 15 Suppl 7, 1-85.

Fiorante, S., Fernandez-Ruiz, M., Lopez-Medrano, F., Lizasoain, M., Lalueza, A., Morales, J.M., San-Juan, R., Andres, A., Otero, J.R. \& Aguado, J.M. (2011) Acute graft pyelonephritis in renal transplant recipients: incidence, risk factors and longterm outcome. Nephrol. Dial. Transplant., 26, 1065-1073.

Giral, M., Pascuariello, G., Karam, G., Hourmant, M., Cantarovich, D., Dantal, J., Blancho, G., Coupel, S., Josien, R., Daguin, P., Mechineau, S. \& Soulillou, J.P. (2002) Acute graft pyelonephritis and long-term kidney allograft outcome. Kidney Int., 61, 1880-1886.

Goldstein, D.R., Tesar, B.M., Akira, S. \& Lakkis, F.G. (2003) Critical role of the Toll-like receptor signal adaptor protein MyD88 in acute allograft rejection. J. Clin. Invest., 111, 15711578.

Goya, N., Tanabe, K., Iguchi, Y., Oshima, T., Yagisawa, T., Toma, H., Agishi, T., Ota, K. \& Takahashi, K. (1997) Prevalence of urinary tract infection during outpatient follow-up after renal transplantation. Infection, 25, 101-105.

Inston, N.G. \& Cockwell, P. (2002) The evolving role of chemokines and their receptors in acute allograft rejection. Nephrol. Dial. Transplant., 17, 1374-1379.

Kamath, N.S., John, G.T., Neelakantan, N., Kirubakaran, M.G. \& Jacob, C.K. (2006) Acute graft pyelonephritis following renal transplantation. Transpl. Infect. Dis., 8, 140-147.

Kidney Disease: Improving Global Outcomes (KDIGO) Transplant Work Group (2009) KDIGO clinical practice guideline for the care of kidney transplant recipients. Am. J. Transplant., 9 Suppl 3, S1-155.
Levey, A.S., Stevens, L.A., Schmid, C.H., Zhang, Y.L., Castro, A.F. 3rd., Feldman, H.I., Kusek, J.W., Eggers, P., Van Lente, F., Greene, T. \& Coresh, J.; CKD-EPI (Chronic Kidney Disease Epidemiology Collaboration) (2009) A new equation to estimate glomerular filtration rate. Ann. Intern. Med., 150, 604-612.

Ljungman, P., Griffiths, P. \& Paya, C. (2002) Definitions of cytomegalovirus infection and disease in transplant recipients. Clin. Infect. Dis., 34, 1094-1097.

Locke, J.E., Zachary, A.A., Warren, D.S., Segev, D.L., Houp, J.A., Montgomery, R.A. \& Leffell, M.S. (2009) Proinflammatory events are associated with significant increases in breadth and strength of HLA-specific antibody. Am. J. Transplant., 9, 2136-2139.

Massy, Z.A., Guijarro, C., Wiederkehr, M.R., Ma, J.Z. \& Kasiske, B.L. (1996) Chronic renal allograft rejection: immunologic and nonimmunologic risk factors. Kidney Int., 49, 518-524.

Meier-Kriesche, H.U., Schold, J.D., Srinivas, T.R. \& Kaplan, B. (2004) Lack of improvement in renal allograft survival despite a marked decrease in acute rejection rates over the most recent era. Am. J. Transplant., 4, 378-383.

Palmer, S.C., Sciancalepore, M. \& Strippoli, G.F. (2011) Trial quality in nephrology: how are we measuring up? Am. $J$. Kidney Dis., 58, 335-337.

Pelle, G., Vimont, S., Levy, P.P., Hertig, A., Ouali, N., Chassin, C., Arlet, G., Rondeau, E. \& Vandewalle, A. (2007) Acute pyelonephritis represents a risk factor impairing long-term kidney graft function. Am. J. Transplant., 7, 899-907.

Rabkin, D.G., Stifelman, M.D., Birkhoff, J., Richardson, K.A., Cohen, D., Nowygrod, R., Benvenisty, A.I. \& Hardy, M.A. (1998) Early catheter removal decreases incidence of urinary tract infections in renal transplant recipients. Transplant. Proc., 30, 4314-4316.

Rubin, R.H. (1994) Infection in the organ transplant recipient. In Clinical approach to infection in the compromised host, 3rd ed., edited by Rubin, R.H., Young, L.S. \& Russell, P. Plenum Publishing Corporation, New York, pp. 629-705.

Rubin, R.H. \& Tolkoff-Rubin, N.E. (1991) The impact of infection on the outcome of transplantation. Transplant. Proc., 23, 2068-2074.

Sagalowsky, A.I., Ransler, C.W., Peters, P.C., Dickerman, R.M., Gailiunas, P., Helderman, J.H., Hull, A.R. \& Atkins, C. (1983) Urologic complications in 505 renal transplants with early catheter removal. J. Urol., 129, 929-932.

Sagedal, S., Nordal, K.P., Hartmann, A., Sund, S., Scott, H., Degre, M., Foss, A., Leivestad, T., Osnes, K., Fauchald, P. \& Rollag, H. (2002) The impact of cytomegalovirus infection and disease on rejection episodes in renal allograft recipients. $\mathrm{Am}$. J. Transplant., 2, 850-856.

Schmaldienst, S. \& Horl, W.H. (1998) Bacterial infections after renal transplantation. Contrib. Nephrol., 124, 18-33; discussion 34-42.

VanBuskirk, A.M., Burlingham, W.J., Jankowska-Gan, E., Chin, T., Kusaka, S., Geissler, F., Pelletier, R.P. \& Orosz, C.G. (2000) Human allograft acceptance is associated with immune regulation. J. Clin. Invest., 106, 145-155.

Veronese, F.V., Noronha, I.L., Manfro, R.C., Edelweiss, M.I., Goldberg, J. \& Goncalves, L.F. (2004) Prevalence and immunohistochemical findings of subclinical kidney allograft rejection and its association with graft outcome. Clin. Transplant., 18, 357-364. 